\title{
Informed consent in deep brain stimulation - ethical considerations in a stress field of pride and prejudice
}

\author{
Tobias Skuban ${ }^{1 *}$, Katja Hardenacke' ${ }^{1}$ Christiane Woopen² and Jens Kuhn' \\ Department of Psychiatry and Psychotherapy, University of Cologne, Cologne, Germany \\ 2 Research Unit Ethics, Institute for the History of Medicine and Medical Ethics, University of Cologne, Cologne, Germany \\ *Correspondence: tobias.skuban@uk-koeln.de
}

The story of psychosurgery is one of great visions, groundbreaking ideas, and heroic acts; similarly it is a story of a great rise, a deep fall, and a cautious resurrection. For a long time, psychosurgery mainly had an experimental character and was dominated by anecdotal reports. In the aftermath of Fulton and Jabobsen's presentation of their results of a series of neurosurgical experiments performed with primates (Kopell and Rezai, 2003) during the International Neurological Congress in London in 1935, a considerable amount of ethically as well as scientifically doubtful surgical interventions were carried out in humans, occasionally even by medically uneducated personnel (Feldman and Goodrich, 2001). In this context one might paradigmatically mention prefrontal lobotomies, which virtually were advertised as magic bullet for all sorts of psychiatric diseases mainly in the 1940s and 1950s (Feldman et al., 2001; Kopell and Rezai, 2003; Mashour et al., 2005). Issues of informed consent frequently were neglected (Feldman and Goodrich, 2001; Pippard, 2001; Huys et al., 2010), critical side effects of the operation were concealed in many cases (Feldman and Goodrich, 2001) and the procedure even was offered to patients considered as criminally insane in exchange for their freedom (Lowinger, 1987). It was not long after Egas Moniz shared the Nobel Prize for medicine "for his discovery of the therapeutic value of prefrontal leucotomies in certain psychoses" in 1949 (Anonymous, 1949) when the public opinion of psychosurgery changed and questionable practices were unmasked (Heller et al., 2006).

Prompted by growing public criticism, a lack of a sufficient theoretical foundation, the uncertainty of its therapeutic value and severe side effects, the Department of Health, Education, and Welfare (Public Health Service) released strict restrictions regarding the usage of leucotomy in 1978 (Department of Health, Education, and Welfare, 1978); back then, many other nations already had prohibited this technique. While in the aftermath of the approval of chlorpromazine as first medicament for the treatment of psychiatric diseases in 1954 psychopharmacological therapy progressively began to revolutionize the psychiatric world, surgical methods for the treatment of psychiatric diseases involving gross damage of brain tissue were abandoned. However, encouraged by former success with invasive methods and supported by a growing knowledge regarding neuroanatomy and neural circuits underlying psychiatric and neurological diseases, novel and innovative surgical techniques came up. By now the somewhat prestressed term "psychosurgery" gave way to the broader idea of "neuromodulation," which summarizes not only invasive methods like deep brain stimulation (DBS) and vagus nerve stimulation, but also noninvasive techniques such as transcranial magnetic stimulation.

The ambivalent history of psychosurgery in mind, it is utterly comprehensible that even a reversible though (minimally) invasive technique like DBS reactivates ancient fears. Furthermore, with the observation of psychiatric side effects following DBS of the subthalamic nucleus in patients suffering from Parkinson's disease in the late 1990s (Bejjani et al., 1999; Hariz et al., 2010; Kuhn et al., 2010) psychiatric diseases came in the focus of DBS. Particularly since this amelioration of possible indications of DBS, the to some extent disreputable inheritance of psychosurgery has been brought up frequently.

However, DBS has not only proven to be an effective tool for the therapy of movement disorders such as Parkinson's disease, essential tremor, and dystonia, but it also has been successfully applied for the treatment of various psychiatric disorders such as obsessive-compulsion disorder (OCD), depression, Gilles-de-la-Tourette Syndrome, alcoholism, minimal conscious states, and Alzheimer's dementia. (Freund et al., 2009; Kuhn et al., 2010; Laxton et al., 2010).

A considerable amount of ethical skepticism culminates in the question of whether and how patients suffering from occasionally debilitating psychiatric diseases are capable of giving fully and freely their informed consent to a partly experimental procedure like DBS; we use the term "experimental" with precaution, but it should be kept in mind that there still is a considerable need for further research especially on its long-term therapeutic value with respect to its usage in psychiatric disorders (Hall and Carter, 2011).

Particularly patients with Alzheimer's disease may be limited in certain cognitive dimensions and this restriction could endanger their ability to completely understand all the implications connected with DBS. Beyond that, cognitive impairment is a common finding in patients with depression which could be linked to a dysfunction of the prefrontal cortex in interaction with subcortical regions (Clark et al., 2009); this dysfunction may result in deficits of attention, perception, concentration, and memory, hereby leading to a significant ambivalence of the patient. Moreover, patients suffering from substance abuse frequently are impaired with respect to tasks that involve highly goal-directed behavior; just recently it has been hypothesized that this deficit may be a result of a dysfunctional hypocretin system in the lateral thalamus (Boutrel et al., 2010). Due to this psychiatric condition, these patients might be constricted in their free decision making process.

Furthermore, many questions regarding DBS are still unanswered yet, for which reason it frequently is considered as a last resort when other therapeutic strategies could not be of substantial help. In this situation the desperate hope for ultimate relief may unduly affect a patient's ability to give his 
or her consent (Glannon, 2010): this aspect exemplarily is emphasized by the fact that OCD patients have to suffer up to $8 \mathrm{~h}$ a day from typical symptoms of their disease to be accepted as possible candidates for DBS (Glannon, 2010). Additionally, the media's perception of DBS and its therapeutic potential tend to be euphoric and occasionally too optimistic. Contrariwise, psychosurgery's frightful history not infrequently is picked out as the central theme of novels and movies (cp. "One Flew Over the Cocoo's Nest," 1975 or “Shutter Island," 2010), which might be a source of inadequate fright for patients and their family members.

We go along with Lang and Widner's (2002) suggestion that "surgery should never be offered to a patient until ... [a] realistic understanding is fully established." Beauchamp and Childress (2001) and Berg et al. (2001) found that informed consent implies three basic requests: (1) all medically relevant information about diagnosis and prognosis of a patient's disease, the therapy, its potential risks and alternative therapies must be disclosed. (2) The patient should have the mental capacity to understand his or her situation and the presented information. (3) The patient must not be coerced or compelled, but autonomously decides about a treatment on the basis of the information disclosed. Regarding what has been discussed above, a patient and his or her family members might be prejudiced and influenced in many ways considering DBS. In addition, due to the underlying psychiatric disease, the patient might lack the mental capacity to fully comprehend his or her condition. Considering all this, envisaging DBS bears the risk that a patient's autonomy, i.e., his or her capacity to determine freely what action should be taken, if any, might be endangered. The concept of autonomy is closely connected to personal uniqueness (Breden and Vollmann, 2004) - so what if this uniqueness is affected by disease and possibly by prejudice as well? Even though this challenge is not unique to DBS or even to DBS in psychiatric diseases, the specific history of DBS, the complex connotations of a patient suffering from a psychiatric illness and potentially existing prejudice of the patient or his or her relatives, urgently call for detailed ethical examinations, highly skilled physicians, and more specific instruments for the assessment of a patient's capacity.

The MacArthur Competence Assessment Tool-Treatment (MacCAT-T) currently is regarded as psychiatry's gold standard for the determination of a patient's decision making competence. However, it has been reasonably criticized: the underlying construct of "competence" evaluated by the MacCAT- T is dominated by cognitive criteria, whereas emotional and biographical factors and a patient's values are ignored, although these dimensions might be of substantial importance during a decision making process (Breden and Vollmann, 2004). No alternative tool has been developed so far, so there is a high and urgent need for further endeavor in the design of proper assessment tools, which should include an extension of the cognition-based construct of competence proposed by the MacCAT-T.

\section{REFERENCES}

Anonymous. (1949). News and views. Nobel Prize for physiology and medicine for 1949. Nature 4179, 947.

Beauchamp, T., and Childress, J. (2001). Principles of Biomedical Ethics, 5th Edn. Oxford: Oxford University Press.

Bejjani, B. P., Damier, P., Arnulf, I., Thivard, L., Bonnet, A. M., Dormont, D., Cornu, P., Pidoux, B., Samson, Y., and Agid, Y. (1999). Transient acute depression induced by high-frequency deep-brain stimulation. N. Engl. J. Med. 340, 1476-1480.

Berg, J. W., Appelbaum, P. S., Lidz, C. W., and Parker, L. S. (2001). Informed Consent: Legal Theory and Clinical Practice, 2nd Edn. New York: Oxford University Press.

Boutrel, B., Cannella, N., and De Lecea, L. (2010). The role of hypocretin in driving arousal and goal-oriented behaviors. Brain Res. 1314, 103-111.

Breden, T. M., and Vollmann, J. (2004). The cognitive based approach of capacity assessment in psychiatry: a philosophical critique of the MacCAT-T. Health Care Anal. 12, 273-283; discussion 265-272.

Clark, L., Chamberlain, S. R., and Sahakian, B. J. (2009). Neurocognitive mechanisms in depression: implications for treatment. Annu. Rev. Neurosci. 32, 57-74.

Department of Health, Education, and Welfare. (1978). Determination of Secretary Regarding Recommendation on Psychosurgery of the National Commission for the Protection of Human Subjects of Biomedical and Behavioral Research. Fed. Regist.43, 221. Feldman, R. P., Alterman, R. L., and Goodrich, J. T. (2001). Contemporary psychosurgery and a look to the future. J. Neurosurg. 95, 944-956.
Feldman, R. P., and Goodrich, J. T. (2001). Psychosurgery: a historical overview. Neurosurgery 48, 647-657; discussion 657-649.

Freund, H. J., Kuhn, J., Lenartz, D., Mai, J. K., Schnell, T., Klosterkötter, J., and Sturm, V. (2009). Cognitive functions in a patient with Parkinson-dementia syndrome undergoing deep brain stimulation. Arch. Neurol. 66, 781-785.

Glannon, W. (2010). Consent to deep brain stimulation for neurological and psychiatric disorders. J. Clin. Ethics 21, 104-111.

Hall, W., and Carter, A. (2011). Is deep brain stimulation a prospective "cure" for addiction? F1000 Med. Rep. 3, 4.

Hariz, M. I., Blomstedt, P., and Zrinzo, L. (2010). Deep brain stimulation between 1947 and 1987: the untold story. Neurosurg. Focus 29, E1.

Heller, A. C., Amar, A. P., Liu, C. Y., and Apuzzo, M. L. (2006). Surgery of the mind and mood: a mosaic of issues in time and evolution. Neurosurgery 59, 720733; discussion 733-729.

Huys, D., Möller, M., Kim, E. H., Huff, W., Klosterkötter, J., Timmermann, L., Woopen, C., and Kuhn, J. (2010). Historische Grundlagen der Tiefen Hirnstimulation bei psychiatrischen Erkrankungen. Nervenarzt (in press).

Kopell, B. H., and Rezai, A. R. (2003). Psychiatric neurosurgery: a historical perspective. Neurosurg. Clin. N. Am. 14, 181-197, vii.

Kuhn, J., Grundler, T. O., Lenartz, D., Sturm, V., Klosterkötter, J., and Huff, W. (2010). Deep brain stimulation for psychiatric disorders. Dtsch Arztebl Int 107, 105-113.

Lang, A. E., and Widner, H. (2002). Deep brain stimulation for Parkinson's disease: patient selection and evaluation. Mov. Disord. 17 Suppl 3, 94-101.

Laxton, A. W., Tang-Wai, D. F., McAndrews, M. P., Zumsteg, D., Wennberg, R., Keren, R., Wherrett, J., Naglie, G., Hamani, C., Smith, G. S., and Lozano, A. M. (2010). A phase I trial of deep brain stimulation of memory circuits in Alzheimer's disease. Ann. Neurol. 68, 521-534.

Lowinger, P. (1987). Two comments on psychosurgery. N. Engl. J. Med. 316, 114-115.

Mashour, G. A., Walker, E. E., and Martuza, R. L. (2005). Psychosurgery: past, present, and future. Brain Res. Brain Res. Rev. 48, 409-419.

Pippard, J. S. (2001). Leucotomy: a qualified defence of “then". QJM 94, 451.

Received: 31 December 2010; accepted: 18 April 2011; published online: 29 April 2011.

Citation: Skuban T, Hardenacke K, Woopen $C$ and Kuhn J (2011) Informed consent in deep brain stimulation - ethical considerations in a stress field of pride and prejudice. Front. Integr. Neurosci. 5:7. doi: 10.3389/ fnint.2011.00007

Copyright (C) 2011 Skuban, Hardenacke, Woopen and Kuhn. This is an open-access article subject to a nonexclusive license between the authors and Frontiers Media SA, which permits use, distribution and reproduction in other forums, provided the original authors and source are credited and other Frontiers conditions are complied with. 